\title{
Analysis of Transposable Elements in Coccidioides Species
}

\author{
Theo N. Kirkland ${ }^{1, *}$, Anna Muszewska ${ }^{2}$ (i) and Jason E. Stajich ${ }^{3}$ (i) \\ 1 Departments of Pathology and Medicine, School of Medicine, University of California, San Diego, \\ CA 92037, USA \\ 2 Institute of Biochemistry and Biophysics, Polish Academy of Sciences, 02-106 Warsaw, \\ Poland; musze@ibb.waw.pl \\ 3 Department of Microbiology and Plant Pathology, Institute for Integrative Genome Biology, \\ University of California-Riverside, Riverside, CA 92521, USA; jason.stajich@ucr.edu \\ * Correspondence: tkirkland@ucsd.edu; Tel.: +1-858-459-7471
}

Received: 29 November 2017; Accepted: 11 January 2018; Published: 19 January 2018

\begin{abstract}
Coccidioides immitis and C. posadasii are primary pathogenic fungi that cause disease in immunologically-normal animals and people. The organism is found exclusively in arid regions of the Southwestern United States, Mexico, and South America, but not in other parts of the world. This study is a detailed analysis of the transposable elements (TE) in Coccidioides spp. As is common in most fungi, Class I and Class II transposons were identified and the LTR Gypsy superfamily is the most common. The minority of Coccidioides Gypsy transposons contained regions highly homologous to polyprotein domains. Phylogenetic analysis of the integrase and reverse transcriptase sequences revealed that many, but not all, of the Gypsy reverse transcriptase and integrase domains clustered by species suggesting extensive transposition after speciation of the two Coccidiodies spp. The TEs were clustered and the distribution is enriched for the ends on contigs. Analysis of gene expression data from C. immitis found that protein-coding genes within $1 \mathrm{kB}$ of $h A T$ or Gypsy TEs were poorly expressed. The expression of C. posadasii genes within $1 \mathrm{kB}$ of Gypsy TEs was also significantly lower compared to all genes but the difference in expression was smaller than C. immitis. C. posadasii orthologs of C. immitis Gyspsy-associated genes were also likely to be TE-associated. In both C. immitis and C. posadasii the TEs were preferentially associated with genes annotated with protein kinase gene ontology terms. These observations suggest that TE may play a role in influencing gene expression in Coccidioides spp. Our hope is that these bioinformatic studies of the potential TE influence on expression and evolution of Coccidioides will prompt the development of testable hypotheses to better understand the role of TEs in the biology and gene regulation of Coccidioides spp.
\end{abstract}

Keywords: fungus; Coccidioides spp.; genomics; transcriptome; transposable elements

\section{Introduction}

We are reporting an analysis of the predicted transposable elements (TE) in the pathogenic fungi Coccidioides immitis and Coccidioides posadasii and the potential relationship of TEs with gene expression. Coccidioides spp. are found in the soil and associated with kangaroo rats in the desert regions of the southwestern US, Mexico, and Central and South America [1]. There are two species, C. immitis and C. posadasii that have been identified by DNA polymorphism and genome sequencing [2,3]. The two species are morphologically indistinguishable. Coccidioides spp. are haploid fungi and lack a described sexual phase although there is molecular evidence for recombination and genes coding for mating type loci has been identified [3-5]. These fungi have unusual life stages where they form spores within mycelia and differentiate into spherules, a rarely observed morphology in fungi, once inside a mammalian host. Coccidioides spp. grow in desert soil and the arthroconidia developed from desiccated 
hyphae when dispersed by the wind can cause disease in mammals, including human beings [6]. Like the other primary pathogenic fungi, Coccidioides spp. are dimorphic; in the mammalian host arthroconidia differentiate to spherules which mature by isotropic growth into large structures that reproduce by releasing endospores. This organism is one of the very few fungi that can cause disease in immunocompetent people. More than 30\% of human infections are symptomatic, usually causing respiratory symptoms $[7,8]$. A significant fraction of infections can disseminate beyond the lungs and cause disseminated disease which can be fatal. Hosts that survive an infection can form granuloma of walled off spherules that lay dormant until the host undergoes an immune deficiency or expires of other causes [8].

There have been a small number of studies of the transcriptome of mycelia (the saprobic form) and spherules (the parasitic form) [9]. These studies used spherules produced in vitro, rather than in animals. In vitro production of spherules involves a defined media, elevated temperature and increased $\mathrm{CO}_{2}$ tension compared to the growth of mycelia [10]. The spherules produced in vitro appear identical to those in vivo by microscopy, but it is not currently known whether these express a similar gene expression program.

These transcription studies identified $13-22 \%$ of Coccidioides spp. genes that were up-regulated as mycelia differentiate into spherules [11]. One study found that transcripts of heat shock protein 30, polysaccharide deacetylase (Arp2/3 complex), spherule outer-wall glycoprotein, and others were up-regulated [9]. One hundred fifty genes were up-regulated in both studies [12]. These include transcripts of 4-hydroxyphenylpyruvate dioxygenase (a gene that is required for dimorphism in many fungi) [13], polysaccharide deacetylase (Arp2/3 complex), $\beta$-(1,4)-amylase, and many other genes in metabolic pathways of complex carbohydrate remodeling. Keto-reductase, and the major facilitator super family transporter family genes were also up-regulated. Several gene families, including some members of the protein kinase family, were down-regulated in spherules [11].

Transposable elements (TEs) are ubiquitous mobile genetic elements found in all eukaryotic genomes [14,15]. TEs were initially thought to have no function (junk DNA), but more recently have been found to be important in genome evolution, gene duplication and a variety of epigenetic phenomena, including influencing expression of a variety protein coding genes and transcriptional response to stresses [16-18]. In some eukaryotes, including insects, vertebrates and especially plants more than half of the genome consists of transposons [16,19]. The fraction of TEs in most fungal genomes varies from 3-20\% [20]. However, in extreme cases such as Blumeria graminis, $85 \%$ of the genes are TEs [21].

Most TE have been classified into Class I and Class II. Class I TEs are retrotransposons that require an RNA intermediate for transposition. Class II or DNA transposons do not require a RNA intermediate and typical DNA TEs insert into new locations by a cut and paste mechanism [20,22].

TEs have been further classified into superfamilies. The long terminal repeats (LTRs) are made up of Gypsy, and Copia. DNA transposons are classified into at least 17 superfamilies and encode a $\mathrm{DDE} / \mathrm{D}$ domain found in all transposases [23]. The most common TEs found in fungal genomes are Gypsy, Copia, and Tc1-Mariner [24,25]. Functional LTR transposons have open reading frames (ORFs) coding for gag, pol, and env (in endogenous retroviruses). The pol ORF codes for reverse transcriptase (with integrase, reverse transcriptase, and RNAse $\mathrm{H}$ protein coding domains) and an aspartic protease required for polypeptide maturation. The entire element is flanked by LTRs. Many LTR transposons have lost one or more functional ORFs required for transposition and thereby lose the ability to replicate autonomously. Long interspersed nuclear repeats (LINE) are another type of Class I transposons that usually possess polyA-tails but are not flanked by LTRs. Intact LINE retrotransposons usually encode two ORFs; the first with a RNA binding domain and the second with endonuclease and reverse transcriptase domains. In fungi, the two most common Class II TE are Tc/Mar and $h A T$ superfamilies $[26,27]$. These are comprised of a DDE transposase with a characteristic transposase dimerization domain flanked by very short terminal inverted repeats [26,28]. 
Owing to the importance of this fungal pathogen, Coccidioides spp. were one of the first dimorphic fungi to have a sequenced genome [3,29]. Sequencing of $C$. immitis and C. posadasii genomes by Sanger sequencing technologies produced relatively complete chromosome-scale genome maps. The assembly of $C$. immitis strain RS is considered more complete than C. posadasii $\mathrm{C} 735$ based on the scaffolds of assembly contigs [3]. Additional lower coverage genome sequencing of multiple strains of $C$. immitis and $C$. posadasii has been performed to better examine the diversity of these species. In two studies the total repetitive content of multiple isolates of $C$. immitis and C. posadasii was estimated to be from $8-21 \%$ of the genome, with many individual TE insertions specific to one assembly [3,25].

Due to differences in genome annotation applied to the initial two Coccidioides spp. genomes, TEs were handled and masked out with different stringencies so the TE content of the C. immitis as compared to $C$. posadasii cannot be directly compared from the published annotation. In addition, databases and methods for TE detection and annotation have improved, so a common and consistent bioinformatics approach in each species is necessary to make comparisons. One study focused on LTR TE's in fungi including Coccidioides spp. explored their content from a genome-ecology perspective and found that the genomic proportion of Class II TEs was highly variable across the Ascomycota [25]. Comparison of $C$. immitis and C. posadasii found a relatively similar TE content while a close relative, the nonpathogenic Uncinocarpus reesii, had a much lower TE content. One major component of the TE content in the Coccidioides spp. genomes are two closely-related families of Gypsy transposons that were found in isolates of both $C$. immitis and C. posadasii. This suggests that these transposons have been retained in the Coccidioides spp. genomes since the species diverged 5 mYA ago.

We have characterized the TEs in Coccidioides spp. and investigated the relationship of TEs and nearby genes in Coccidioides spp. taking advantage of the genomic and transcriptomic resources of this closely related pair of species. As the TE content likely varies more than the gene content, these data provide an opportunity to compare transcript expression of a set of orthologous gene loci differing by their proximity to a transposable element. The currently available transcription studies were performed with the RS strain of C. immitis and the C735 strain of C. posadasii, so we have focused on these two strains.

\section{Materials and Methods}

\subsection{Genomes}

The genomes and annotations of $C$. immitis RS strain and C. posadasii C735 strain were obtained from FungiDB [30,31]. TE annotation was performed using RepeatMasker [32] which identified TEs based on the RepBase reference library and REPET to support de novo TE identification [33]. The results of these annotation and supporting pipeline scripts are provided in the Github repository [34].

\subsection{Analysis tools}

Calculation of GC content and ORF prediction was done using tools in Galaxy [35]. Prediction of polyprotein domains was done by blastx analysis of Gypsy TEs against the Swiss-Prot database. A BLASTX hit of $<10^{-8}$ to a polyprotein was considered positive. Phylogenetic relationships of Gypsy domains were assessed by performing multiple alignments using Clustal X; the relations were displayed using the Interactive Tree of Life tools [36]. TEs were mapped to contigs using igv [37].

Identification of loci within $1 \mathrm{kB}$ of TEs and Gene Ontology term enrichment identification of genes in C. immits or C. posadasii were performed within FungiDB. Tables of normalized gene expression values of protein coding genes based on RNAseq of $C$. immitis and C. posadasii mycelia and spherules from prior studies were also obtained from the FungiDB presentation of Whiston et al. results [9]. The data are expressed as $\log _{2}$ transformed unique fragments per kilobase of transcript per million mapped reads (FKPM).

Statistical comparisons of the association of gene expression and presence of TEs was performed with ANOVA and the Dun's post-test in R. Reported $p$-values are corrected by the Bonferroni 
adjustment for multiple testing. Scripts are provided in the Github repository associated with this publication [34].

\section{Results}

The total repetitive DNA content of C. immitis and C. posadasii DNA identified in this study is $17-19 \%$ of the genome (Table 1), very similar to the previously reported values for these genomes [3,25,29]. All the identified repetitive elements are listed in Table S1. About $70 \%$ of the repetitive DNA is encoded by Class I LTR elements, Class II elements and LINE elements. Gypsy is the most common type of TE found in both species, and is typically the most abundant in many fungi [24,25].

Table 1. Predicted TEs in Coccidioides spp.

\begin{tabular}{|c|c|c|c|c|c|c|c|c|}
\hline \multirow[b]{2}{*}{ Type } & \multicolumn{4}{|c|}{ C. immitis } & \multicolumn{4}{|c|}{ C. posadasii } \\
\hline & Number & $\begin{array}{l}\text { Mean } \\
\text { Length }\end{array}$ & $\begin{array}{c}\text { ORFs > } \\
300 \text { nt (\%) }\end{array}$ & $\begin{array}{c}\text { GC } \\
\text { Content } \\
(\%)\end{array}$ & Number & $\begin{array}{l}\text { Mean } \\
\text { length }\end{array}$ & $\begin{array}{c}\text { ORF > } \\
300 \text { nt (\%) }\end{array}$ & $\begin{array}{c}\text { GC } \\
\text { Content } \\
(\%)\end{array}$ \\
\hline DNA/TcMar & 286 & 884 & $113(40)$ & 37 & 575 & 991 & $456(79)$ & 36 \\
\hline -Ant1 & 63 & & & & 31 & & & \\
\hline -Fot1 & 134 & & & & 430 & & & \\
\hline -Pogo & 27 & & & & 29 & & & \\
\hline$-\mathrm{Tc1}$ & 66 & & & & 83 & & & \\
\hline $\mathrm{DNA} / h A T$ & 100 & 2416 & $80(80)$ & 36 & 37 & 1232 & $15(40)$ & 31 \\
\hline LTR/Gypsy & 1204 & 2089 & 1557 (130) & 33 & 1199 & 2046 & 1387 (116) & 34 \\
\hline LTR/Copia & 287 & 1351 & $151(52)$ & 38 & 190 & 937 & $131(69)$ & 39 \\
\hline LINE & 364 & 1331 & $239(66)$ & 28 & 225 & 1237 & $144(64)$ & 31 \\
\hline
\end{tabular}

The relative proportions of TE and total repetitive DNA are similar in C. immitis and C. posadasii (Table 1). Notable differences include more $h A T$ elements and fewer TcMar elements in C. immitis as compared to C. posadasii. Many TEs contain ORFs longer than 300 nucleotides; the ratio of ORF to TE was lowest in TcMar and highest in Gypsy. Some Gypsys contained more than one ORF. The GC content of DNA coding for TEs is 28-39\%, markedly lower than the average GC content for the total Coccidioides spp. genomes (46\%), which is consistent with a RIP mechanism as has been suggested by others $[3,38]$.

We focused on Gypsy TEs for a more detailed analysis. The presence of domains was analyzed by BLASTX searching the Swiss-Prot database for homolog to LTR polyproteins (Evalue $\leq 10^{-8}$ ). Using this approach, 338 of $1204(28 \%)$ C. immitis Gypsy and 22\% of C. posadasii TEs contain regions homolgous to a polyprotein domain (Table 2). In both species, Gypsy elements lacking a polyprotein domain were more likely to be within $1 \mathrm{kB}$ of a locus, suggesting that Gypsy TEs lacking polyprotein domains were found in more gene-rich regions than those with polyprotein domains.

Table 2. Polyprotein domains in Gypsy TEs.

\begin{tabular}{lcccccc}
\hline & \multicolumn{3}{c}{ C. immitis } & \multicolumn{3}{c}{ C. posadasii } \\
\hline & Total & Pol Domain & None & Total & Pol Domain & None \\
\hline Number of TEs & 1204 & $338(28 \%)$ & $866(72 \%)$ & 1199 & $260(22 \%)$ & $938(78 \%)$ \\
Associated loci & 571 & $60(11 \%)$ & $511(89 \%)$ & 341 & $24(7 \%)$ & $317(91 \%)$ \\
\hline
\end{tabular}

Reverse transcriptase (RT) and integrase (INT) domains were aligned using Clustal $X$ to investigate their evolution and a Bootstap N-J tree inferred in order to investigate their evolution. The trees representing the relationships of RT and INT domains of the Gypsy polyproteins from C. immitis and C. posadasii are shown in Figure 1. The two trees show that for the most part RT and INT domains of the two species are more closely related within the species than between species. The species-specific 
divergence suggests that transposition has occurred after species diverged, followed by independent evolution of the domains in each of the Coccidioides lineages. It has been noted in previous comparative genomics studies of multiple Coccidioides strains that the genomes differed by individual insertions, indicating that transposable elements have been active in multiple strains [3,25].

RT

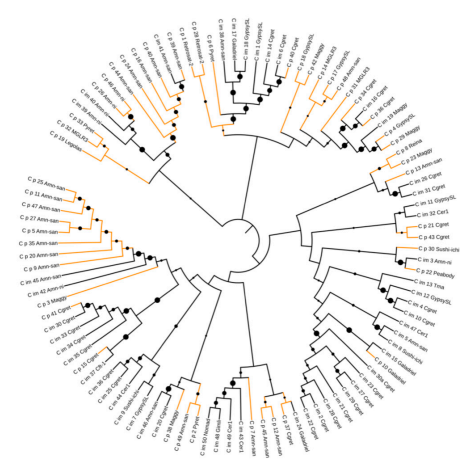

INT

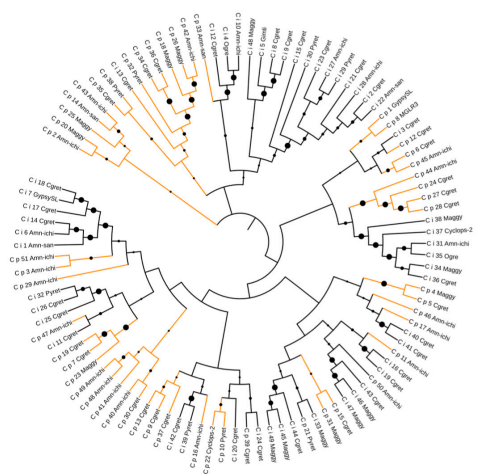

Figure 1. Phylogenetic relationship between RT and INT domains in C. immitis and C. posadasii. The black lines represent C. immitis Gypsy RT and INT domains; the orange lines represent C. posadasii Gypsy RT and INT domains. The size of the black dot represents the bootstrap value.

The distribution of TEs along the C. immitis and C. posadasii contigs in shown in Figure 2. There is a tendency in both species for TEs to occur in clusters enriched at the ends of contigs. The clusters are shown more dramatically as histograms of the number of $C$. immitis TEs plotted against position on contigs 1 and 2 (bins of $5 \%$ length) (Figure 3). The mapping pattern of C. immitis and C. posadasii TEs is similar, although many C. posadasii TEs are found on very short contigs, which likely reflects the difficulty in assembling repetitive DNA or a less robust $C$. posadasii assembly. DNA and LTR TEs appear to be randomly distributed within the clusters. Overlapping TEs are relatively uncommon; only $273(13 \%)$ of the C. immitis and $190(9 \%)$ of the C. posadasii TEs are nested.

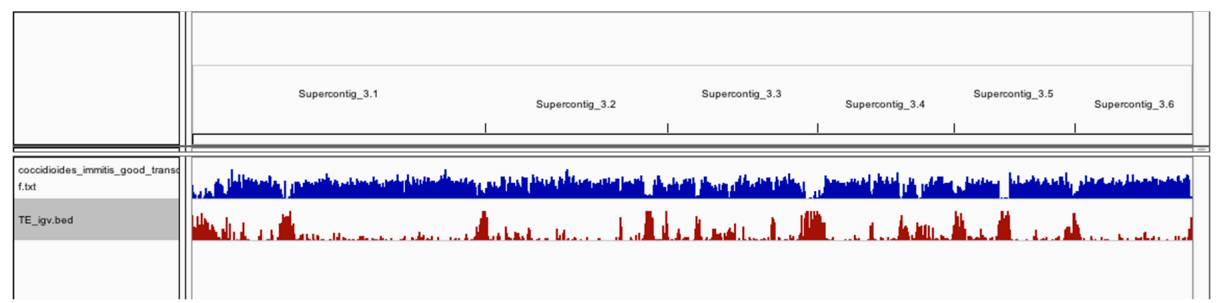

(a)

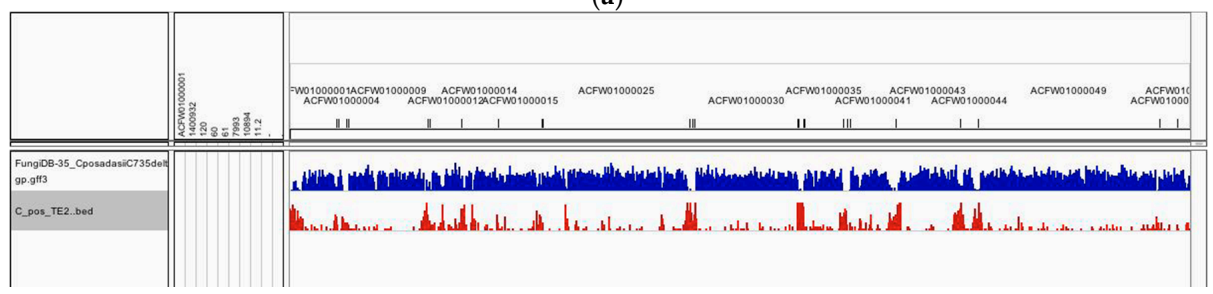

(b)

Figure 2. The genomic distribution of protein-coding loci (blue track) and the TEs (red track) in C. immitis (a) and C. posadasii (b) assemblies. These data show an inverse relationship between predicted genes and TEs and the tendency of TEs to cluster at the ends of contigs, reflecting both assembly difficulties and potential preferential accumulation regions. The C. immitis genome is mapped on six contigs; C. posadasii on 20. 

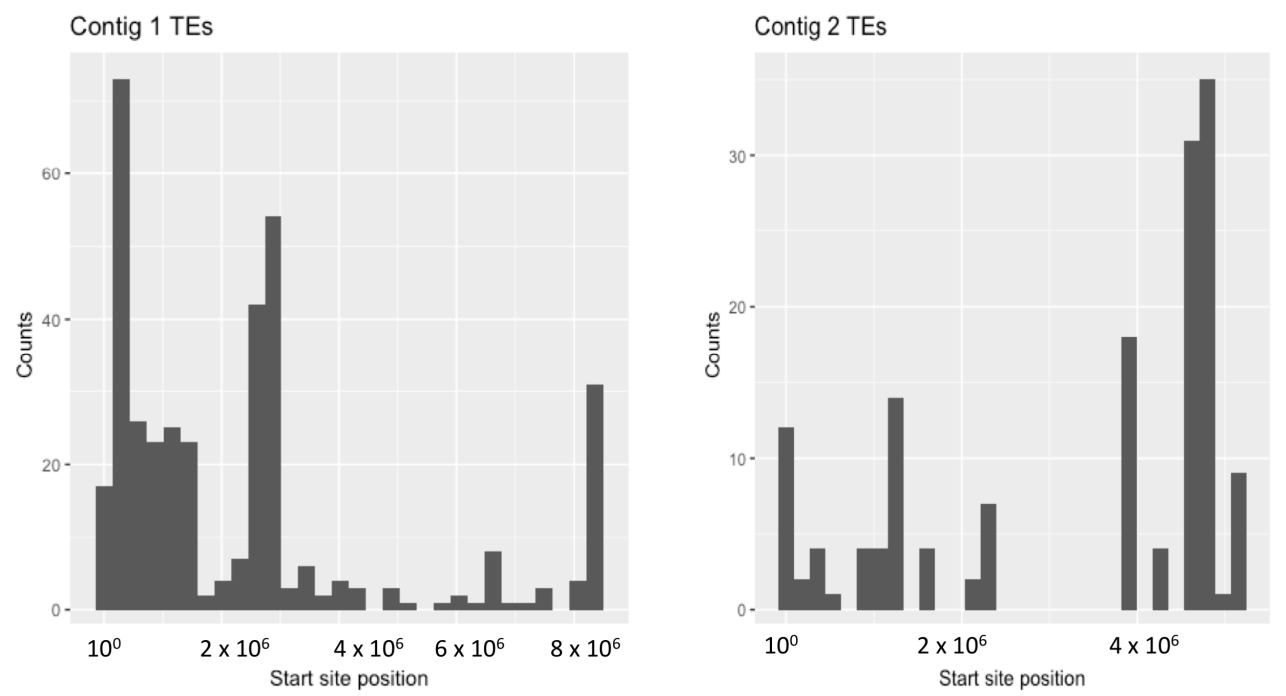

Figure 3. Histogram showing the frequency of TEs in the two largest $C$. immitis contigs. The number of C. immitis TEs is plotted on the $\mathrm{Y}$ axis and the position on contigs 1 and 2 is plotted on the $\mathrm{Y}$ axis. A bin width of $5 \%$ of the contig length was used.

There are a total of 902 C. immitis protein-encoding loci flanked by a TE within $1 \mathrm{kB}$. Many of these loci are in the lowest quartile of expression compared to all loci. The mean expression level of C. immitis genes within $1 \mathrm{kB}$ of a TE is significantly less (3.60 FPKM) than the level of expression in controls (4.29 FPKM) $\left(p<1 \times 10^{-4}\right)$ (Figure 4). The level of expression for the spherule stage is shown and essentially identical results were found when exploring the expression in hyphae. Expression of C. immitis genes within $1 \mathrm{kB}$ of four or more TEs was very low $\left(p<1 \times 10^{-15}\right)$. In C. posadasii, 773 loci were associated with TEs. C. posadasii loci associated with multiple TEs were also poorly expressed $\left(p<10^{-2}\right)$, but but the proportion of poorly expressed genes was much lower than in C. immitis.

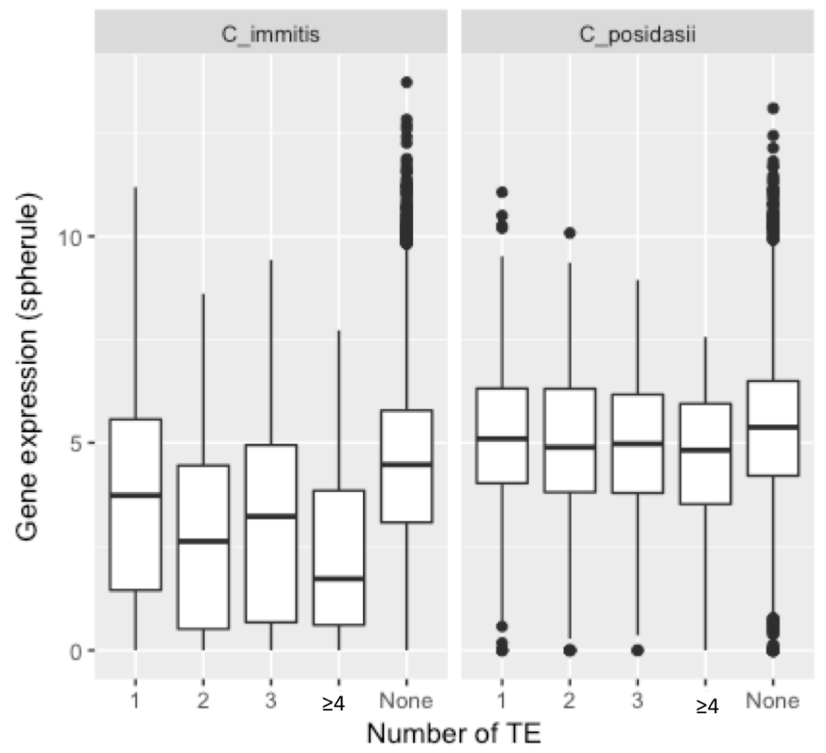

Figure 4. Expression (median values $\log _{2}$ FPKM) of C. immitis and C. posadasii loci within $1 \mathrm{kB}$ of one or more TE. The $p$-values for gene expression of all C. immitis groups flanked by at least one TE compared to control expression levels ("None") are less than $1 \times 10^{-4}$. The $p$-values of $C$. posadasii gene expression of genes flanked by at least two TEs is $7 \times 10^{-3}$ compared to the control ("None"). The remaining C. posadasii gene expression values are not significantly lower than the control value. 
Fifty-five $C$. immitis genes were within $1 \mathrm{kB}$ of four or more TEs. Seventeen of $55(31 \%)$ of these genes were close to the end of a contig (within $300 \mathrm{bp}$ ). Twenty-seven of the 55 genes had orthologs in C. posadasii and 10 of the $27(37 \%)$ C. posadasii homologs were also close to the end of a contig.

Twenty-six of the 27 C. posadasii orthologs are within $1 \mathrm{kB}$ of at least one TE and 17/27 are within $1 \mathrm{kB}$ of four or more TEs (Table 3). To address this question further, 295 C. posadasii orthologs of the 571 C. immitis loci flanked by a Gypsy TE were identified. One-hundred eighty-one (61\%) of these C. posadasii genes were also within $1 \mathrm{kB}$ of a TE. Since only 772 of a total of $7255(11 \%)$ of $C$. posadasii loci were associated with TEs, these data suggest that many more orthologous loci are also associated with TE than would be expected by chance (chi-square $<10^{-10}$ ).

Table 3. C. posadasii orthologous protein-encoding loci associated TEs.

\begin{tabular}{cccccc}
\hline & \multicolumn{5}{c}{ Number of TEs } \\
\hline C. posadasii orthologs & $\geq 4$ & 3 & 2 & 1 & None \\
27 & 17 & 2 & 5 & 4 & 1 \\
\hline
\end{tabular}

The association of different superfamilies of C. immitis and C. posadasii TEs with the level of expression of nearby loci is shown in Figure 5. In C. immitis, loci within $1 \mathrm{kB}$ of Gypsy and $h A T$ TEs are the most poorly expressed. Loci within $1 \mathrm{kB}$ of TcMar, Copia or LINE TEs are also expressed at a lower level than the average for all loci. TEs did not have an effect on the relative expression of genes in hyphae compared to spherules. The association of poor gene expression with TEs was much less impressive in C. posadasii. Gypsy TEs were associated with relatively poorly expressed loci $\left(p<5 \times 10^{-3}\right)$ but none of the other superfamilies were. The relationship of $h A T$ to gene expression in C. posadasii could not be determined because only eight loci were within $1 \mathrm{kB}$ of this TE.

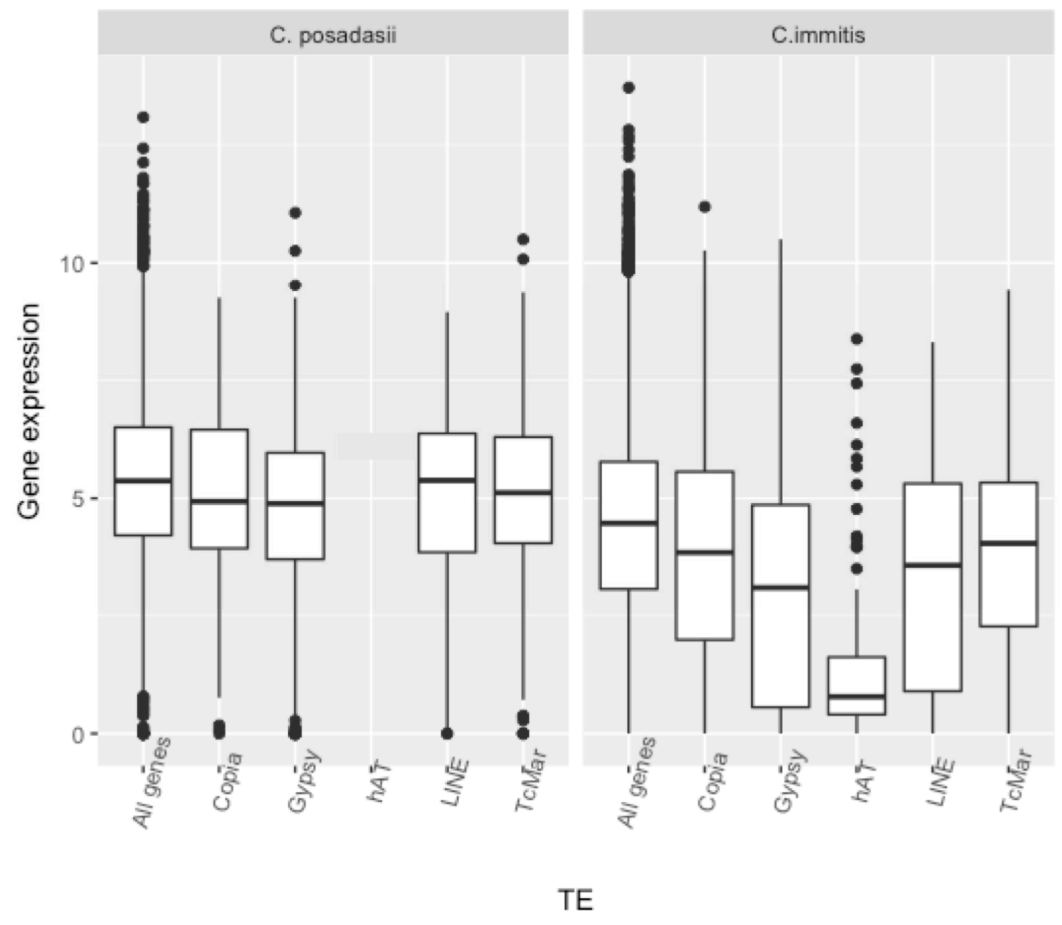

Figure 5. Mean expression values ( $\log _{2}$ FPKM) of $C$. immitis and C. posadasii loci within $1 \mathrm{kB}$ of TE superfamilies compared to all loci. The $p$-values for $C$. posadasii genes associated with Gypsy were $5 \times 10^{-3}$ and all others were not significant. The $p$-values for $C$. immitis genes associated with any TE superfamily were all $\leq 1 \times 10^{-4} ; p$-values for $C$. immitis genes associated with Gypsy or $h A T$ TEs were $\leq 1 \times 10^{-10}$. 
In C. immitis, the relationship of locus expression to the relative position of the TEs depends upon the TE superfamily (Table 4). Genes with a $5^{\prime}$ flanking Gypsy or contained within a Gypsy TEs are expressed at a lower level than $3^{\prime}$ flanking TE. Genes within $1 \mathrm{kB}$ of hAT TEs also have low expression levels regardless of relative location. However, the relative location of genes to TcMar or Copia TE's does not seem to influence expression. In C. posadasii, the flanking direction of the Gypsy TE to the locus did not appear to be correlated with the level of expression.

Table 4. Relationship of gene location to TE to gene expression in C. immitis.

\begin{tabular}{cccccccc}
\hline & Control & \multicolumn{2}{c}{ Upstream $^{\text {a }}$} & \multicolumn{2}{c}{ Overlap $^{\mathbf{b}}$} & \multicolumn{2}{c}{ Downstream $^{\mathbf{c}}$} \\
\hline & Mean & Number & Mean & Number & Mean & Number & Mean \\
\hline All genes & 4.032 & 992 & & 773 & & & \\
TcMar & & 115 & 3.734 & 131 & 3.759 & 115 & 3.734 \\
hAT & & 75 & 1.134 & 73 & 1.135 & 77 & 1.292 \\
Copia & & 119 & 3.242 & 69 & 3.343 & 137 & 4.229 \\
Gypsy & & 272 & 3.027 & 217 & 2.001 & 312 & 2.156 \\
\hline
\end{tabular}

${ }^{a}$. Gene upstream of TE; ${ }^{b}$. TE overlaps gene; ${ }^{c}$. Gene downstream of TE.

The FungiDB Gene Ontology Enrichment tool was used to test whether there was a bias in the predicted function of TE-associated genes. TE-associated genes from both C. immitis and C. posadasii, were enriched for phosphorylation and protein phosphorylation Gene Ontology (GO) terms (Table 5). The TE-associated protein phosphorylation genes have a similar expression level in hyphae and spherules.

Table 5. GO enrichment analysis of genes associated with TEs.

\begin{tabular}{|c|c|c|c|c|c|}
\hline \multirow[b]{2}{*}{ ID } & \multirow[b]{2}{*}{ Name } & \multicolumn{2}{|c|}{ C. immitisb } & \multicolumn{2}{|c|}{ C.posadasii } \\
\hline & & Odds Ratio & $p$ (Bonferroni) & Odds Ratio & $p$ (Bonferroni) \\
\hline GO:0016310 & Phosphorylation & 3.35 & $1.43 \times 10^{-7}$ & 3.34 & $7.35 \times 10^{-7}$ \\
\hline GO:0006468 & protein phosphorylation & 3.47 & $1.56 \times 10^{-7}$ & 3.60 & $2.10 \times 10^{-6}$ \\
\hline GO:0036211 & protein modification process & 2.72 & $3.87 \times 10^{-6}$ & 2.48 & $2.90 \times 10^{-4}$ \\
\hline GO:0006464 & $\begin{array}{c}\text { cellular protein } \\
\text { modification process }\end{array}$ & 2.72 & $3.87 \times 10^{-6}$ & 2.48 & $2.90 \times 10^{-4}$ \\
\hline GO:0006796 & $\begin{array}{l}\text { phosphate-containing } \\
\text { compound metabolic process }\end{array}$ & 2.45 & $1.17 \times 10^{-5}$ & 2.07 & $4.41 \times 10^{-3}$ \\
\hline GO:0006793 & phosphorus metabolic process & 2.43 & $1.36 \times 10^{-5}$ & 2.05 & $5.00 \times 10^{-3}$ \\
\hline
\end{tabular}

Forty-one TE-associated C. immitis genes were classified with the protein phosphorylation functional GO term 0006468 (listed in Table S2). These genes were found dispersed over all contigs. Fourteen were described as CMGC or CMGC/SRPK kinases, nine as serine/threonine protein kinases, 11 as hypothetical proteins, and the remainder as other kinases. Forty-two $C$. immitis genes associated with TE were classified with the phosphorylation functional GO term 0016310 (Table S2). Twenty-six of these were also annotated with the protein phosphorylation GO term. Thirteen of the 42 genes were classified as CMGC or CMGC/SRPK kinases, nine as serine/threonine kinases, 11 as hypothetical proteins, and the remainder as other kinases.

\section{Discussion}

This analysis of the genomes of Coccidioides spp. finds that TEs comprise $17-19 \%$ of the genome, a similar proportion of repetitive DNA found in previous studies $[3,25,29]$. Coccidioides spp. like all fungi, contains both Type I retrotransposons and Type II DNA transposons. The most common TE identified was Gypsy, as has been previously reported [3,25]. All TE superfamilies contain some open reading frames $>300 \mathrm{nt}$; Gypsy TEs contains the highest proportion of ORFs and TcMar the 
lowest. Only 20-30\% of Gypsy TEs contain ORFs with polyprotein domains indicating that most are non-autonomous copies that have extensive modification. Non-autonoumous Gypsy TEs lacking polyprotein domains were more frequently found within $1 \mathrm{kB}$ of protein coding genes, suggesting that active TEs may not be tolerated in actively transcribed regions, although the mechanism for exclusion or genome defense of genic regions requires further exploration. Phylogenetic analysis of Gypsy reverse transcriptase and integrase showed that the domains tended to cluster within species, but with a significant amount of mixing between species. The tendency for domains to cluster within species could be due to transposition of TEs after the species diverged, as others have reported [3,25]. Presumably, the domains that are closely related between species reflect TEs that were inserted before the species diverged. All TEs have a low GC content, which is consistent with repeat-induced point mutation as previous studies have suggested $[3,38]$.

TEs in a variety of organisms tend to occur in clusters that are predominantly found at the telomeres or centromeres [39,40]. Many of the Coccidioides spp. TEs are found in clusters that contain both Class I and Class II TEs. Only a few of the TEs are nested suggesting that transposition may not be ongoing into targeted locations. Clusters of Coccidioides spp. TEs tend to be found primarily at the ends of contigs, as has been observed in some other fungal genomes [41-43]. Since the location of the centromeres and telomeres in Coccidioides spp. are currently undescribed, it is impossible to comment on association of TEs within or proximal to those structures.

We found that C. posadasii genes that are orthologs of C. immitis Gypsy-associated genes also tend to be TE-associated. C. posadasii orthologs of C. immitis genes flanked by multiple TEs tend to be associated with multiple TEs too. This suggests that insertion of TEs may have preferentially occurred near certain genes. In other organisms LTR transposons have been found to preferentially integrate into regions near a subset of genes [44].

Our analyses point to a common trend of reduced gene expression of loci with nearby TEs, especially in C. immitis. Many genes within $1 \mathrm{kB}$ of a TE are relatively poorly expressed. This effect is most striking if more than one TE is near a gene. The type of TE has an influence as well, with genes near $h A T$ or a Gypsy TEs showing the lowest average expression. The relative position of C. immitis genes to TE is correlated with lower expression if the TE is a Gypsy but not other types of TEs. Furthermore, the function of genes associated with TEs is non-random as there is an enrichment of protein phosphorylation and phosphorylation functional categories.

C. posadasii TE-associated genes are expressed at a more typical level. On average, the expression of genes near multiple TEs was modestly lower than all genes. Comparing the effect of different TE superfamilies, only Gypsy C. posadasii elements showed a significant correlation with reduced gene expression. Only eight genes are within $1 \mathrm{kB}$ of a $h A T$ TE in C. posadasii, limiting the resolution and sufficient observations to test if this class of TEs was also associated with poor expression of loci. Although the mean level of expression of genes associated with TEs is not as low in C. posadasii as in C. immitis, we do not know why. The two species have diverged significantly, which may play a role in the difference.

The significance of the association of multiple TEs or $h A T$ and Gypsy TEs with poorly expressed protein-encoding loci in C. immitis is unclear. It it also not clear what mechanism accounts for this association. One possibility is that some superfamilies of TEs tend to co-localize with poorly-expressed genes. Another is that some TEs suppress gene expression. This data does not distinquish between those possibilities.

TEs have been documented to influence gene expression in many of organisms [33,45-47], often modulating genes that code for stress responses and host defenses $[17,48]$. There are a variety of mechanisms by which TE's can influence gene expression. The most direct mechanism would be inactivation or enhancement of promoter activity influencing gene expression [49]. TE insertions in the UTR could also effect on mRNA stability [16]. DNA methylation can specifically target repetitive regions and may be an important mechanism for gene silencing [50-52]. Although there have been no published studies of DNA methylation in Coccidioides spp., both C. immitis and 
C. posadasii have transcribed homologs of Dim-1 cytosine methylase, supporting the possibility that DNA methylation silencing could provide transposon control. DNA methylation targeting TEs that spreads to neighboring genes could explain the observed reduced expression of genes proximal to TEs. TEs are associated with heterochromatin formation, which could decrease expression of associated loci $[47,53]$. Inhibitory small RNAs are another mechanism that could play a role in targeting transcript repression [54]. There is no direct assessment of RNAi or small RNA activity in Coccidioides spp., although both species contain genes coding for RNAi machinery namely RNA-dependent RNA polymerase, Argonaute and Dicer proteins. It is possible that more than one suppressive mechanism is playing a role for one TE or that different TEs suppress gene activity by different mechanisms.

In contrast to the difference in gene TE-associated gene silencing in C. immitis and C. posadasii, TEs in both species are associated with genes coding for phosphorylation, including protein phosphorylation. It is interesting that many protein kinase genes are down-regulated as C. immitis hyphae differentiate into spherules [11]. The link between TEs and genes coding for phosphorylation in both C. immitis and C. posadasii is consistent with the hypothesis that this association may have occurred before the divergence of the two species and that there may be some evolutionary pressure to maintain that association. A number of TEs in other organisms have been found to preferentially occur at specific sites within the genome. Some of the most common genes associated with TEs code for transfer RNA, ribosomal RNA, silent mating genes and genes involved in the formation of heterochromatin $[44,55,56]$. Some TEs have also been found to preferentially insert near protein phosphorylation genes [57].

In summary, this is a report characterizing the transposable elements in two Coccidioides spp. An association of some TEs with poorly expressed protein-encoding genes in C. imitis and a genomic location association of TEs with phosphorylation enzymes in both species of Coccidioides has been observed. This is a bioinformatic study characterizing TEs and their association with genomic and transcriptomic data. It is our hope that the data will suggest hypotheses about gene regulation in Coccidioides spp. for future experimental testing.

Supplementary Materials: The following are available online at www.mdpi.com/2309-608X/4/1/13/s1. Table S1. C. immitis and C. posadasii repeats. Table S2. C. immitis loci with protein phosphorylation or phosphorylation functional GO terms.

Acknowledgments: We thank Evalina Y. Basenko and Omar Harb for assistance in data queries utilizing FungiDB. Data analyses were performed on the UC Riverside High-Performance Computational Cluster supported by NSF DBI-1429826 and NIH S10-OD016290. Anna Muszewska was supported by the National Science Centre (2017/25/B/NZ2/01880) and Ministry of Science and Higher Education scholarship for outstanding young researchers. Jason E. Stajich was supported by funds from the University of California Multicampus Research Programs and Initiatives "Center for Valley Fever Research".

Author Contributions: Jason E. Stajich and Anna Muszewska identified and characterized the transposable elements. Theo N. Kirkland analyzed the data. All authors participated in writing the manuscript.

Conflicts of Interest: The authors have no conflicts of interest.

\section{References}

1. Teixeira, M.M.; Barker, B.M. Use of Population Genetics to Assess the Ecology, Evolution, and Population Structure of Coccidioides. Emerg. Infect. Dis. 2016, 22, 1022-1030. [CrossRef] [PubMed]

2. Fisher, M.C.; Koenig, G.; White, T.J.; Taylor, J.W. A test for concordance between the multilocus genealogies of genes and microsatellites in the pathogenic fungus Coccidioides immitis. Mol. Biol. Evol. 2000, 17, 1164-1174. [CrossRef] [PubMed]

3. Neafsey, D.E.; Barker, B.M.; Sharpton, T.J.; Park, D.J.; Whiston, E.; Hung, C.-Y.; McMahan, C.; White, J.; Sykes, S.; Heiman, D.; et al. Population genomic sequencing of Coccidioides Fungi reveals recent hybridization and transposon control. Genome Res. 2010, 20, 938-946. [CrossRef] [PubMed]

4. Fraser, J.A.; Tarcha, E.J.; Cole, G.T.; Inglis, D.O.; Sil, A.; Heitman, J. Evolution of the mating type locus: Insights gained from the dimorphic primary fungal pathogens Histoplasma capsulatum, Coccidioides immitis, and Coccidioides posadasii. Eukaryot. Cell 2007, 6, 622-629. [CrossRef] [PubMed] 
5. Mandel, M.A.; Barker, B.M.; Kroken, S.; Rounsley, S.D.; Orbach, M.J. Genomic and population analyses of the mating type loci in Coccidioides species reveal evidence for sexual reproduction and gene acquisition. Eukaryot. Cell 2007, 6, 1189-1199. [CrossRef] [PubMed]

6. Kirkland, T.N.; Fierer, J. Coccidioidomycosis: A reemerging infectious disease. Emerg. Infect. Dis. 1996, 2, 192-199. [CrossRef] [PubMed]

7. Valdivia, L.; Nix, D.; Wright, M.; Lindberg, E.; Fagan, T.; Lieberman, D.; Stoffer, T.; Ampel, N.M.; Galgiani, J.N. Coccidioidomycosis as a common cause of community-acquired pneumonia. Emerg. Infect. Dis. 2006, 12, 958-962. [CrossRef] [PubMed]

8. Nguyen, C.; Barker, B.M.; Hoover, S.; Nix, D.E.; Ampel, N.M.; Frelinger, J.A.; Orbach, M.J.; Galgiani, J.N. Recent advances in our understanding of the environmental, epidemiological, immunological, and clinical dimensions of coccidioidomycosis. Clin. Microbiol. Rev. 2013, 26, 505-525. [CrossRef] [PubMed]

9. Whiston, E.; Zhang Wise, H.; Sharpton, T.J.; Jui, G.; Cole, G.T.; Taylor, J.W. Comparative transcriptomics of the saprobic and parasitic growth phases in Coccidioides spp. PLoS ONE 2012, 7, e41034. [CrossRef] [PubMed]

10. Converse, J.L. Effect of physico-chemical environment of spherulation of Coccidioides immitis in a chemically defined medium. J. Bacteriol. 1956, 72, 784-792. [PubMed]

11. Viriyakosol, S.; Singhania, A.; Fierer, J.; Goldberg, J.; Kirkland, T.N.; Woelk, C.H. Gene expression in human fungal pathogen Coccidioides immitis changes as arthroconidia differentiate into spherules and mature. BMC Microbiol. 2013, 13, 1-15. [CrossRef] [PubMed]

12. Kirkland, T.N. A few shared up-regulated genes may influence conidia to yeast transformation in dimorphic fungal pathogens: Table 1. Med. Mycol. 2016, 54, 648-653. [CrossRef] [PubMed]

13. Boyce, K.J.; McLauchlan, A.; Schreider, L.; Andrianopoulos, A. Intracellular Growth Is Dependent onTyrosine Catabolism in the Dimorphic FungalPathogen Penicillium marneffei. PLoS Pathog. 2015, 11, e1004790. [CrossRef] [PubMed]

14. Fedoroff, N.V. Presidential address. Transposable elements, epigenetics, and genome evolution. Science 2012, 338, 758-767. [CrossRef] [PubMed]

15. Feschotte, C.; Pritham, E.J. DNA Transposons and the Evolution of Eukaryotic Genomes. Annu. Rev. Genet. 2007, 41, 331-368. [CrossRef] [PubMed]

16. Rebollo, R.; Romanish, M.T.; Mager, D.L. Transposable Elements: An Abundant and Natural Source of Regulatory Sequences for Host Genes. Annu. Rev. Genet. 2012, 46, 21-42. [CrossRef] [PubMed]

17. Feng, G.; Leem, Y.-E.; Levin, H.L. Transposon integration enhances expression of stress response genes. Nucleic Acids Res. 2012, 41, 775-789. [CrossRef] [PubMed]

18. Casacuberta, E.; González, J. The impact of transposable elements in environmental adaptation. Mol. Ecol. 2013, 22, 1503-1517. [CrossRef] [PubMed]

19. Biemont, C. A Brief History of the Status of Transposable Elements: From Junk DNA to Major Players in Evolution. Genetics 2010, 186, 1085-1093. [CrossRef] [PubMed]

20. Kempken, F.; Kück, U. Transposons in filamentous Fungi-Facts and perspectives. Bioessays 1998, $20,652-659$. [CrossRef]

21. Parlange, F.; Oberhaensli, S.; Breen, J.; Platzer, M.; Taudien, S.; Šimková, H.; Wicker, T.; Doležel, J.; Keller, B. A major invasion of transposable elements accounts for the large size of the Blumeria graminis f.sp. tritici genome. Funct. Integr. Genom. 2011, 11, 671-677. [CrossRef] [PubMed]

22. Seberg, O.; Petersen, G. A unified classification system for eukaryotic transposable elements should reflect their phylogeny. Nat. Rev. Genet. 2009, 10, 276. [CrossRef] [PubMed]

23. Yuan, Y.-W.; Wessler, S.R. The catalytic domain of all eukaryotic cut-and-paste transposase superfamilies. Proc. Natl. Acad. Sci. USA 2011, 108, 7884-7889. [CrossRef] [PubMed]

24. Santana, M.F.; Silva, J.C.; Mizubuti, E.S.; Araújo, E.F.; Condon, B.J.; Turgeon, B.; Queiroz, M.V. Characterization and potential evolutionary impact of transposable elements in the genome of Cochliobolus heterostrophus. BMC Genom. 2014, 15, 536. [CrossRef] [PubMed]

25. Muszewska, A.; Hoffman-Sommer, M.; Grynberg, M. LTR Retrotransposons in Fungi. PLoS ONE 2011, 6, e29425. [CrossRef] [PubMed]

26. Daboussi, M.-J.; Capy, P. Transposable Elements in Filamentous Fungi. Annu. Rev. Microbiol. 2003, 57, $275-299$. [CrossRef] [PubMed]

27. Grandaubert, J.; Balesdent, M.-H.; Rouxel, T. Evolutionary and Adaptive Role of Transposable Elements in Fungal Genomes, 1st ed.; Elsevier Ltd.: Amsterdam, The Netherlands, 2014; Volume 70, pp. 79-107. 
28. Atkinson, P.W. hAT Transposable Elements. Microbiol. Spectr. 2015, 3, 1-27. [CrossRef] [PubMed]

29. Sharpton, T.J.; Rounsley, S.D.; Gardner, M.J.; Wortman, J.R.; Jordar, V.S.; Maiti, R.; Kodira, C.D.; Neafsey, D.E.; Zeng, Q.; Hung, C.-Y.; et al. Comparative genomic analyses of the human fungal pathogens Coccidioides and their relatives. Genome Res. 2009, 19, 1722-1731. [CrossRef] [PubMed]

30. Harris, T.; Brunk, B.P.; Brestelli, J.; Fischer, S.; Harb, O.S.; Kissinger, J.C.; Li, W.; Nayak, V.; Pinney, D.F.; Stoeckert, C.J.; et al. FungiDB: An integrated functional genomics database for Fungi. Nucleic Acids Res. 2012, 40, D675-D681.

31. FingiDB. Available online: http:/ / fungidb.org/fungidb / (accessed on 10 January 2017).

32. RepeatMasker. Available online: http://www.repeatmasker.org/ (accessed on 6 January 2017).

33. Castanera, R.; López-Varas, L.; Borgognone, A.; LaButti, K.; Lapidus, A.; Schmutz, J.; Grimwood, J.; Pérez, G.; Pisabarro, A.G.; Grigoriev, I.V.; et al. Transposable Elements versus the Fungal Genome: Impact on Whole-Genome Architecture and Transcriptional Profiles. PLoS Genet. 2016, 12, e1006108. [CrossRef] [PubMed]

34. GitHub. Available online: https://github.com/hyphaltip/cocci_repeats/ (accessed on 10 January 2017).

35. Galaxy. Available online: https:/ / usegalaxy.org/ (accessed on 9 January 2017).

36. iTOL. Available online: https:/ /itol.embl.de/ (accessed on 7 January 2017).

37. Integrative Genomics Viewer. Available online: http://software.broadinstitute.org/software/igv/userguide (accessed on 12 October 2017).

38. Clutterbuck, A.J. Genomic evidence of repeat-induced point mutation (RIP) in filamentous ascomycetes. Fungal Genet. Biol. 2011, 48, 306-326. [CrossRef] [PubMed]

39. Baucom, R.S.; Estill, J.C.; Chaparro, C.; Upshaw, N.; Jogi, A.; Deragon, J.-M.; Westerman, R.P.; SanMiguel, P.J.; Bennetzen, J.L. Exceptional Diversity, Non-Random Distribution, and Rapid Evolution of Retroelements in the B73 Maize Genome. PLoS Genet. 2009, 5, e1000732. [CrossRef] [PubMed]

40. Dhillon, B.; Gill, N.; Hamelin, R.C.; Goodwin, S.B. The landscape of transposable elements in the finished genome of the fungal wheat pathogen Mycosphaerella graminicola. BMC Genom. 2014, 15, 1132-1149. [CrossRef] [PubMed]

41. Labbé, J.; Murat, C.; Morin, E.; Tuskan, G.A.; Le Tacon, F.; Martin, F. Characterization of Transposable Elements in the Ectomycorrhizal Fungus Laccaria bicolor. PLoS ONE 2012, 7, e40197. [CrossRef] [PubMed]

42. Yadav, C.B.; Bonthala, V.S.; Muthamilarasan, M.; Pandey, G.; Khan, Y.; Prasad, M. Genome-wide development of transposable elements-based markers in foxtail millet and construction of an integrated database. DNA Res. 2015, 22, 79-90. [CrossRef] [PubMed]

43. Loftus, B.J.; Fung, E.; Roncaglia, P.; Rowley, D.; Amedeo, P.; Bruno, D.; Vamathevan, J.; Miranda, M.; Anderson, I.J.; Fraser, J.A.; et al. The genome of the basidiomycetous yeast and human pathogen Cryptococcus neoformans. Science 2005, 307, 1321-1324. [CrossRef] [PubMed]

44. Devine, S.E.; Boeke, J.D. Integration of the yeast retrotransposon Ty1 is targeted to regions upstream of genes transcribed by RNA polymerase III. Genes Dev. 1996, 10, 620-633. [CrossRef] [PubMed]

45. Elbarbary, R.A.; Lucas, B.A.; Maquat, L.E. Retrotransposons as regulators of gene expression. Science 2016, 351, aac7247. [CrossRef] [PubMed]

46. Wang, X.; Weigel, D.; Smith, L.M. Transposon Variants and Their Effects on Gene Expression in Arabidopsis. PLoS Genet. 2013, 9, e1003255. [CrossRef] [PubMed]

47. Chuong, E.B.; Elde, N.C.; Feschotte, C. Regulatory activities of transposable elements: From conflicts to benefits. Nat. Rev. Genet. 2017, 18, 71-86. [CrossRef] [PubMed]

48. Makarevitch, I.; Waters, A.J.; West, P.T.; Stitzer, M.; Hirsch, C.N.; Ross-Ibarra, J.; Springer, N.M. Transposable Elements Contribute to Activation of Maize Genes in Response to Abiotic Stress. PLoS Genet. 2015, 11, e1004915. [CrossRef] [PubMed]

49. Cowley, M.; Oakey, R.J. Transposable elements re-wire and fine-tune the transcriptome. PLoS Genet. 2013, 9, e1003234. [CrossRef] [PubMed]

50. Zhang, X.; Yazaki, J.; Sundaresan, A.; Cokus, S.; Chan, S.W.L.; Chen, H.; Henderson, I.R.; Shinn, P.; Pellegrini, M.; Jacobsen, S.E.; et al. Genome-wide High-Resolution Mapping and Functional Analysis of DNA Methylation in Arabidopsis. Cell 2006, 126, 1189-1201. [CrossRef] [PubMed]

51. Aramayo, R.; Selker, E.U. Neurospora crassa, a Model System for Epigenetics Research. Cold Spring Harb. Perspect. Biol. 2013, 5, a017921. [CrossRef] [PubMed] 
52. Li, X.; Wang, X.; He, K.; Ma, Y.; Su, N.; He, H.; Stolc, V.; Tongprasit, W.; Jin, W.; Jiang, J.; et al. High-Resolution Mapping of Epigenetic Modifications of the Rice Genome Uncovers Interplay between DNA Methylation, Histone Methylation, and Gene Expression. Plant Cell Online 2008, 20, 259-276. [CrossRef] [PubMed]

53. Lippman, Z.; Gendrel, A.-V.; Black, M.; Vaughn, M.W.; Dedhia, N.; McCombie, W.R.; Lavine, K.; Mittal, V.; May, B.; Kasschau, K.D.; et al. Role of transposable elements in heterochromatin and epigenetic control. Nature 2004, 430, 471-476. [CrossRef] [PubMed]

54. Nicolás, F.E.; Garre, V. RNA Interference in Fungi: Retention and Loss. Microbiol. Spectr. 2016, 4. [CrossRef]

55. Zhu, Y.; Dai, J.; Fuerst, P.G.; Voytas, D.F. Controlling integration specificity of a yeast retrotransposon. Proc. Natl. Acad. Sci. USA 2003, 100, 5891-5895. [CrossRef] [PubMed]

56. Hua-Van, A.; Le Rouzic, A.; Maisonhaute, C.; Capy, P. Abundance, distribution and dynamics of retrotransposable elements and transposons: Similarities and differences. Cytogenet. Genome Res. 2005, 110, 426-440. [CrossRef] [PubMed]

57. Miyao, A. Target Site Specificity of the Tos17 Retrotransposon Shows a Preference for Insertion within Genes and against Insertion in Retrotransposon-Rich Regions of the Genome. Plant Cell Online 2003, 15, 1771-1780. [CrossRef]

(C) 2018 by the authors. Licensee MDPI, Basel, Switzerland. This article is an open access article distributed under the terms and conditions of the Creative Commons Attribution (CC BY) license (http:/ / creativecommons.org/licenses/by/4.0/). 